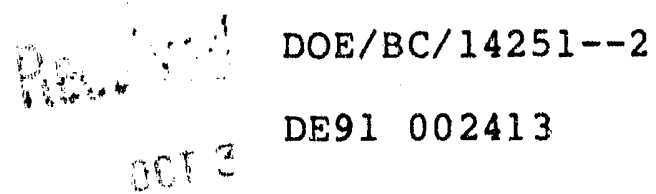

\title{
ANNEX II - RESERVOIR CHARACTERIZATION AND ENHANCED OIL KECOVERY RESEARCH
}

Quarterly Report for the Period

December 1988 - February 1989

\author{
By \\ Gary A. Pope \\ J.H. Herring Centenniai Chair in Petroleum Engineering \\ Chairman and Professor \\ Larry W. Lake \\ Halliburton Annual Professorship in Petroleum \\ Engineering and Shell Distinguished Chair \\ Professor \\ Robert S. Schechter \\ Getty Ou Co. Centennial Chair in Petroleum and \\ Professor of Chemical Engineering and Petroleum Engineering
}

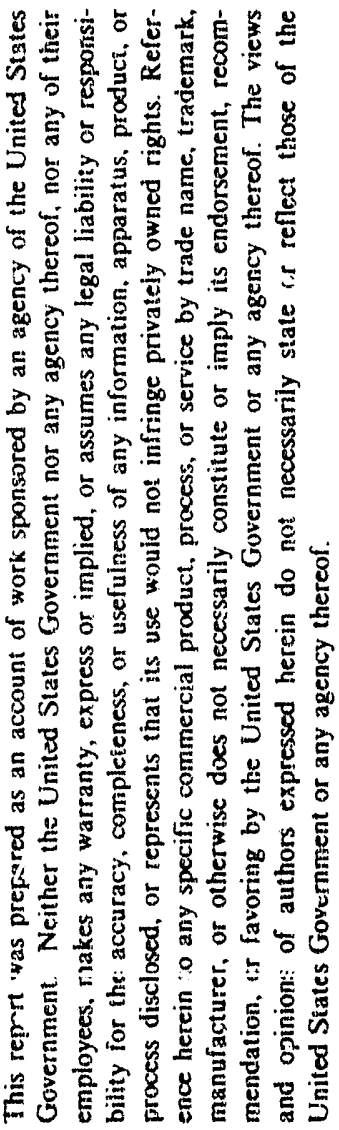

Work Performed under Contraci No. DE-FG22-89BC14251

Jerry F. Casteel, Project Manager

U.S. Departmeni of Energy

Bartlesville Project Office

P.O. Box 1398

Bartlesville, OK 74005

\author{
Prepared by \\ The University of Texas \\ Department of Petroleum Engineering \\ Austin, Texas 78712
}




\section{ANNEX II - RESERVOIR CHARACTERIZATION AND ENHANCED OIL RECOVERY RESEARCH}

Contract No. DE-FG22-89BC14251

The University of Texas at Austin

Austin, Texas

Contract Date: September 1, 1988

Ancicipated Completion: August 31, 1990

Government Award: $\$ 380,000$ (Current Year)

Principal Investigators:

Gary A. Pope

Larry W. Lake

Robert S. Schechter

Technical Project Officer.

Jerry F. Casteel

Bartlesville Project Office

Reporting Period: December 1, 1988 - February 28, 1989 
ANNEX II - RESERVOIR CHARACTERIZATION AND ENHANCED OIL RECOVERY RESEARCH

Contract No. DE-FG22-89BC14251

The University of Texas at Austin

Austin, Texas

Contract Date: September 1, 1988

Anticipated Completion: August 31, 1990

Funding for FY 1988: $\$ 380,000$

Principal Investigators: Gary A. Pope, Larry W. Lake, and Robert S. Schechter Project Monitor: Jerry F. Casteel, Bartlesville Project Office

Reporting Period: Dest mber 1988 - February 1989

\section{Objective}

The objective of this project is to increase our understanding of EOR processes as they relate to realistic reservoir settings for increased efficiencies and decreased risks in known reservoirs in the State of Texas. The primary activities of the Project will include:

(1) Systematic reservoir characterizations.

(2) Modeling and scaleup of chemical flooding techniques.

(3) Gaining a broader understanding and providing fundarnental information on $\mathrm{CO}_{2}$ surfactant phase behavior.

\section{Sumumary of Technical Progress}

\section{Subtask 1 - Systematic Procedure for Reservoir Characterization - Larry W. Lake}

Subtask $1 b$ - Quantification of existing taxonomy through the use of correlation, fractal representation and nonlinear dynamic statistical procedures.

This project deals with developing means to generate analytical pseudo functions for volume averaging in numerical simulation. Preliminary work has indicated that the traditional approach of assuming capillary equilibrium throughout a cross-section is invalid in the limit of large viscous forces. Mixing zones predicted by this analytical method are in general 3-6 times smaller than those exhibited by explicit simulations. Furthermore, the character of the displacement is entirely different. Future work will concentration i $\Omega$ developing a comprehensive theory which handle this discrepancy.

Two other projects are commencing. One project deals with a generalized study of local permeability using the minipermeameter. Since we have a means of generating a large number of non-destructive measurements at our disposal we can now seek the fundamental dependency of perneability of factors other than grain size and sorting. The second project deals with a viable means of incorporating uncertainty into numerical simulation. 


\section{Subtask 2 - Modeling and Scaleup of Chemical Flooding-Gary A. Pope}

Subtask $2 a$ - Perform single well tracer studies to estimate reservoir properties other than those of residual oil saturation.

A two-dimensional radial coordinate option has been added to the University of Texas chemical flooding simulator (UTCHEM). The radial option assumes a horizontal reservoir with a constant pressure outer boundary and a rate specified well at is center. It retains the same formulation as the cartesian-only version of UTCHEM and therefore was added without major changes to the existing code. While all of the complex physical process models required for accurate simulation of chemical flooding have been retained, the current use of the radial option is the investigation of single-well tracer flow. The most common example of this is the single-well backflow tracer method for measuring residual oil saturation. However, the primary focus of this project is not the further study of this particular test, but of backflow tracer methods to determine other reservoir characteristics, such as wettability.

The mathematical formulation of the radial option and its implementation in UTCFIEM has been completed. ${ }^{5}$ Comparisons of simulation results to an analytical solution of the radial convection-dispersion equation show that the simulator accurately models dispersive radial flow, to the point that numerical dispersion control may not be the limiting factor in grid block size. A study of the effects of communicating layers on the residual oil saturation determining tracer test reveals that the effect of transverse dispersion in singlewell backflow tracer tests will be significant in instances of large permeability distributions. A preliminary investigation into the effects of capacitance on single-well backflow tracer iests without a soak period shows that, while the results are sensitive to reasonable changes in the capacitance parameters, interpreting the effects of capacitance on an actual test may be difficult.

Only an example of our results for the effect of transverse dispersion or the single well backflow tracer test are given below. Other results can be found in the thesis ot Descant. 5

One use of the radial option is the simulation of single-well, backflow tracer tests for determination of residual oil saturation. ${ }^{1}$ The theory of the test and its procedure is well documented. ${ }^{2}$ A slug of water containing an ester (primary tracer) is injected into a reservoir that is at or near residual oil saturation, followed by more water. The well is shut in, allowing the ester to partially hydrolyze into alcohol (secondary tracer). The well is then produced. Because the ester partitions into the immobile oil much more than the alcohol does, the ester concentration peak will be chromatographically retarded compared to that of the alcohol. This separation is a function of residual oil saturation. Usually, a third non-partitioning non-reacting tracer is included to check material balance.

If certain idealized assumptions are made, including no dispersion and negligible injection and production times, residual oil saturation may be directly calculated from the produced tracer concentration histories. In most instances, however, histories must be matched by a numerical model in order to estimate residual oil saturation. 
Several finite-difference simulation studies of the residual oil sanuration tracer test have been published. In these studies, non-communicating layers are assumed in layered reservoirs. Therefore, potentially important mechanisms such as transverse dispersion are neglected. In this brief study of the residual oil saturation tracer test, no attempt at matching or analyzing field data from the literature has been made. Instead, the sensitivity of simulations of the test to layering and crossflow is examined, since this has not been published.

The reservoir and tracer parameters chosen for this study, taken from a test analyzed by Bragg, et al. ${ }^{3}$ and Deans and Majoros 2,4 are given in Table 1 . The ethyl acetate to ethanol reaction is assumed to be of first order and irreversible with [ETOH] $=k[E T A C]$ where $k$ is the reaction constant with units of days ${ }^{-1}$ and the concentration units are vol\%. Drift velocity was negligible, as indicated by produced tracer concentration histories. Both groups simulated the test as a homogeneous reservoir and estimated the residual oil saturation to be about $13 \%$. However, the test was not simulated exactly by either group. Bragg, et al. pointed out that the simulated production history of the ethyl acetate (primary tracer) was normalized downward to match the field data peak value, in order to compensate for loss of the tracer to lift gas in the welibore. They apparently did not make this correction with the other tracers, which were alcohols. Deans and Majoros stated that the absolute value of the tracer concentration histories are not so important as the location of the peaks (as furctions of produced volume). They therefore disregarded the actual injected concentrations and arbitrarily scaled their simulation results to match the data peaks, so that both the primary and secondary tracer histories were corrected. In simulations with UTCHEM, a good match of the material balance tracer history was possible, but the peaks of the simulated histories of both the primary and secondary tracers were at least twice as great as their respective field data peaks. Deans and Majoros did not report the scaling factors they used.

A base case simulation run was made with UTCHEM using the same input as given in Table 1. A grid refinement study showed that 18 radial grid blocks with a constant $\Delta r$ of $2.1 \mathrm{ft}$ gave results comparable to 60 grid blocks with a $\Delta \mathrm{r}$ of $0.6 \mathrm{ft}$. The 60 grid block run took $77.2 \mathrm{CPU}$ seconds, while the 18 grid block run took $17.8 \mathrm{CPU}$ seconds. A longitudinal dispersivity of $1 \mathrm{ft}$ best fit the material balance tracer data. This radial grid and value of longitudinal dispersivity were used in subsequent multilayer runs.

Figures 1, 2, and 3 show the effects of transverse dispersivity on a five-layer reservoir. The layers are of equal thickness and have permeabilities of $800,500,1400,200$, and $11.00 \mathrm{md}$. Results for transverse dispersivities from 0 to $1 \mathrm{ft}$ are presented. This case was more seusitive to transverse dispersivity than a two-layer case. ${ }^{5}$ This was due not only to the greater number of layers and larger permeability variation, but also to the layer arrangement. A large difference in permeability between adjacent layers is needed to allow enough dispersive mixing between layers to significantly affect produced concentrations. ${ }^{5}$ However, in such cases large errors in the measured residuai oil saturation are possible due to the traditional neglect of transverse dispersion and such cases thus merit a more careful analysis. 


\section{REEERENCES}

1. Tomich, J.F., Dalton, R.L., Deans, H.A., and Shallenberger, L.K., "Single-Well Tracer Method to Measure Residual Oil Saturation," Journal of Petroleum Technology, Feb, 1973, pp. 211-218.

2. Deans, H.A., and Majoros, S., "The Single-Well Chemical Tracer Method for Measuring Residual Oil Saturation," U.S. DOE Report BC/20006-18, Oct., 1980.

3. Bragg, J.R., Carlson, L.O., and Atterbury, J.H., "Recent Applications of the Single Well Tracer Method for Measuring Residual Oil Saturation," SPE 5805, presented at the Third SPE Symposium on Improved Oil Recovery, Tulsa, OK, Mar. 22-24, 1976.

4. Deans, H.A., and Majoros S., "Single-Well Chemical Tracer Test Simulator Handbook: Improved Accuracy and Interpretation for Residual Oil Saturation Measurement," U.S DOE Report BC/20006-14, June, 1980.

5. Descant, F., "Simulation of Single-Well Tracer Test - (UTCHEM)," Masters Thesis, The University of Texas at Austin, August 1989. 


\section{Table 1 Reservoir and Tracer Data for Residual Oil Saturation Test}

\begin{tabular}{ll} 
Thickness & $20 \mathrm{ft}$ \\
Forosity & 0.34 \\
Permeability & $800 \mathrm{md}$ \\
Water saturation & 0.13 \\
Wellbore radius & $0.25 \mathrm{ft}$ \\
Slug size & $1000 \mathrm{bbl}$ \\
Total injection & $1980 \mathrm{bbl}$ \\
Injection rate & $1000 \mathrm{bbl} /$ day \\
Total Production & $3900 \mathrm{bbl}$ \\
Production rate & $650 \mathrm{bbl} / \mathrm{day}$ \\
Primary to secondary reaction rate & \\
\multicolumn{1}{c}{ constant (first-order) } & 0.015 days ${ }^{-1}$
\end{tabular}

Tracer Injected Concentration Partition Coefficient (oil/water)

Methanol (material balance) 0.5 vol\% (slug only) 0

$\begin{array}{lll}\text { Ethyl Acetate (primary) } & 1.0 \mathrm{vol} \% & 6.7\end{array}$

Ethanol (secondary tracer) $\quad 0 \quad 0$ 


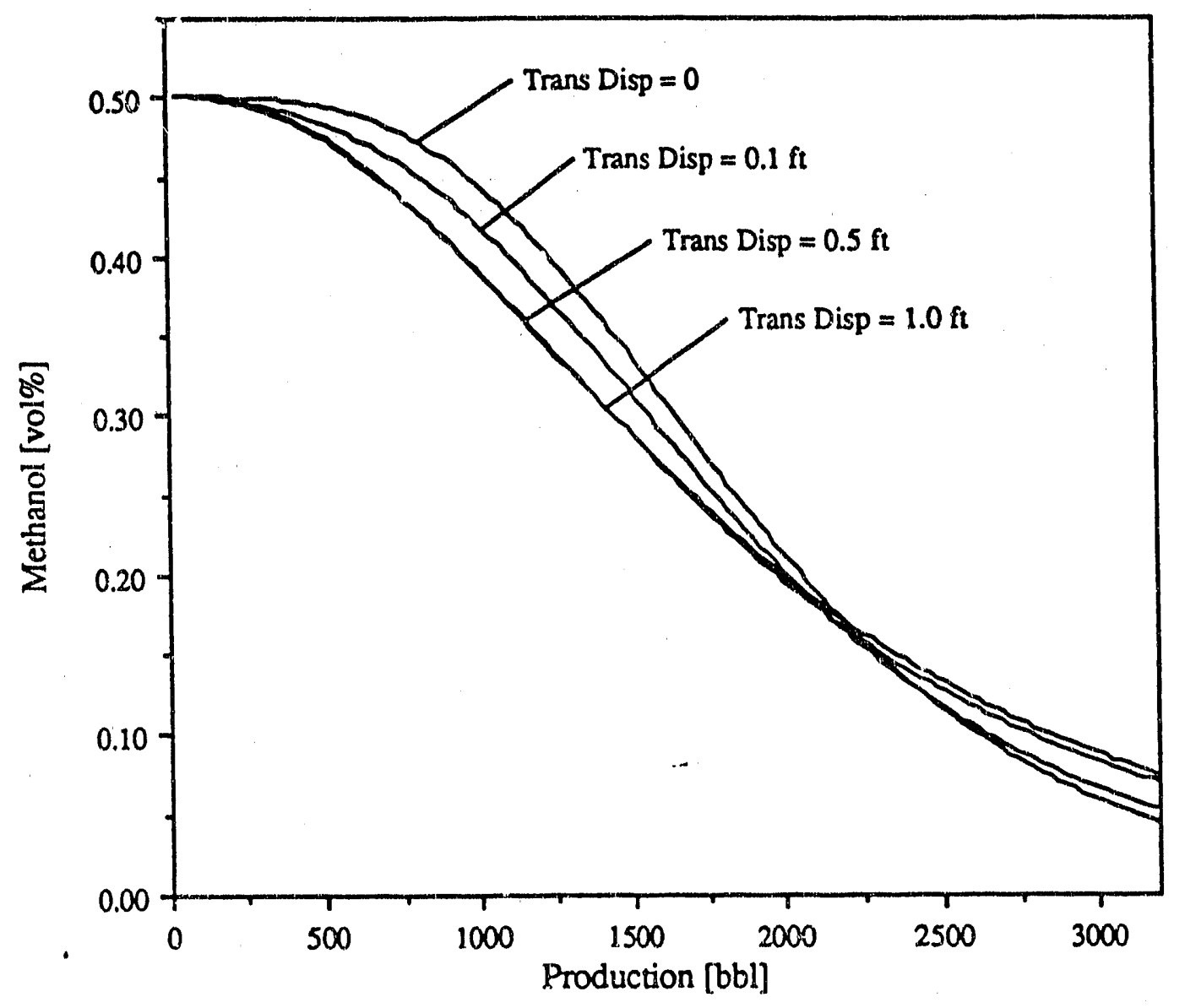

Figure 1 Effect of Transverse Dispersivity on Material Balance Tracer for Five-Layer Case 


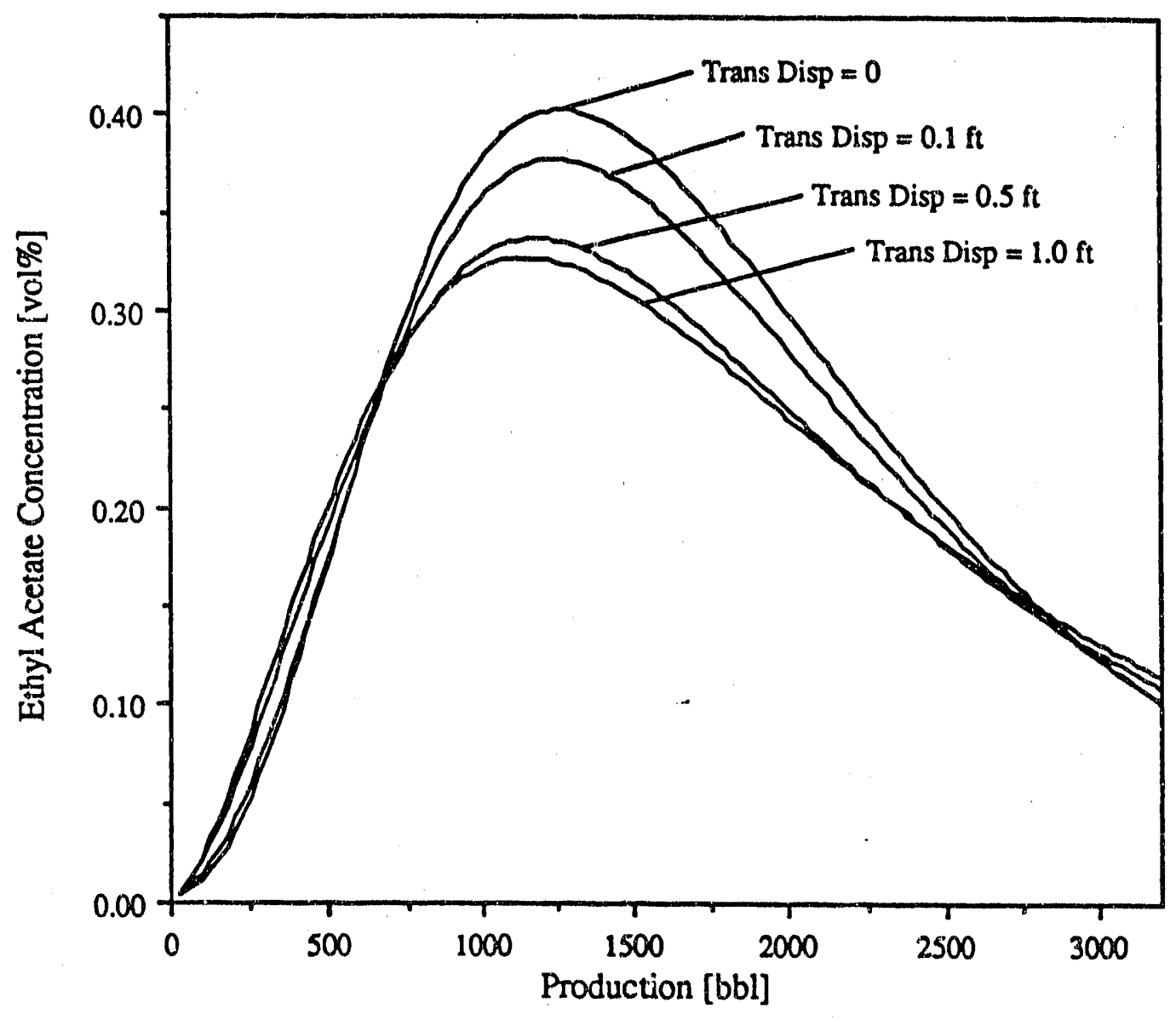

Figure 2 Effect of Transverse Dispersivity on Primary Tracer for Five-Layer Case 


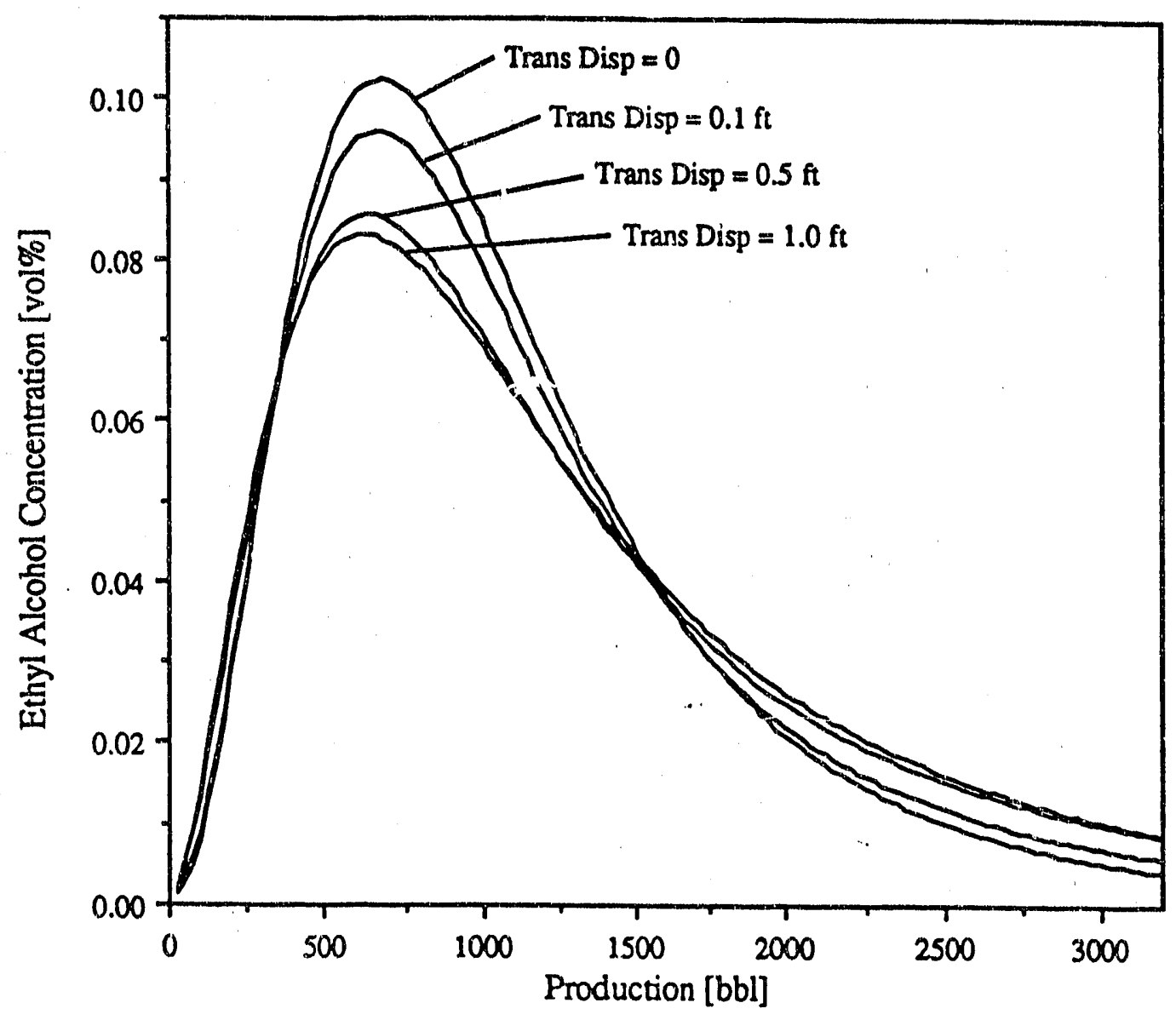

Figure 3 Effect of Transverse Dispersivity on Secondary Tracer for Five-Layer Case 


\section{Subtask $3-\mathrm{CO}_{2}$ - Surfactant Phase Behavior - Robert S. Schechter}

Subtask $3 b$ - A study of oil- $\mathrm{CO}_{2}$-water-surfactant interactions as a means of developing theoretical models that relate to the phase behavior of the particular system considered, and to assure that a particular surfactant will function properly over a wide range of conditions.

This report contains an overview of the theory of surfactant adsorption under development. A number of other models have been tested and the one outlined here appears to yield the best description of the complex processes involved in adsorption.

\section{Theoretical Overview}

The basis of the theory of surfactant adsorption under development is the Complexation Site-Binding Model (CSBM), which has been widely accepted as a suitable description of the electrical double layer at the metal oxide/aqueous solution interface. ${ }^{1-6}$ The CSBM treats amphoteric sites on the surface as if they were chemical species in solution, "reacting" or complexing, with potential-determining and indifferent electrolyte ions subject to equilibrium constants.

These constants are used in conjunction with a model of the double layer to describe the behavior of the interface in aqueous solution. The double layer is modeled as three planes separated by layers of constant capacitance: (1) the surface (o) plane, where potential-determining ions are adsorbed; (2) the inner Helmholtz (b) plane, where complexed indifferent ions are adsorbed; and (3) the ovier Helmholtz (d) plane, where the diffuse layer begins. Knowledge of the equilibrium constants, together with the values of the capacitances of the two layers (which in the CSBM are adjustable parameters), permits calculation of charge densities and potentials at all three planes as a function of $\mathrm{pH}$ and electrolyte concentration. The potential at the diffuse layer is assumed to be the same value derived from zeta-potential measurements.

To account for the adsorption of surfactant, two new "reactions" have been introduced to the model. The first reaction is simply the complexation of a negative surfactant ion with a positive site on the surface, subject to a complexation equilibrium constant $K_{S}^{\text {int* }}$ :

$$
\begin{aligned}
& \mathrm{MOH}_{2}^{+} \mathrm{S}^{-} \stackrel{\mathrm{K}_{\mathrm{S}}^{\mathrm{int} \mathrm{t}^{*}}}{\leftrightarrow} \mathrm{MOH}^{*}+\mathrm{H}_{\mathrm{O}}^{+}+\mathrm{S}_{B}^{-} \\
& \mathrm{K}_{\mathrm{S}}^{\mathrm{int}}=\frac{\left(\mathrm{MOH}^{*}\right)\left(\mathrm{H}_{0}^{+}\right)\left(\mathrm{S}_{B}^{-}\right)}{\left(\mathrm{MOH}_{2}^{+} \mathrm{S}^{-}\right)}
\end{aligned}
$$


The second reaction is the complexation of a neutral surfactant ion-counterion pair with a neutral site near an existing surfactant complex, subject to a different complexation equilibrium constant $\mathrm{K}_{\mathrm{SC}}^{\mathrm{int} \text { : }}$

$$
\begin{aligned}
& \mathrm{MOHS}^{-} \mathrm{C}^{+} \cdot \mathrm{MOH}_{2}^{+} \mathrm{S}^{-} \leftrightarrow \mathrm{MOH}^{*}+\mathrm{S}_{B}^{-}+\mathrm{C}_{B}^{+}+\mathrm{MOH}_{2}^{+} \mathrm{S}^{-} \\
& \mathrm{K}_{\mathrm{SC}}^{\mathrm{int}}=\frac{\left(\mathrm{MOH}^{*}\right)\left(\mathrm{C}_{B}^{+}\right)\left(\mathrm{S}_{B}^{-}\right)\left(\mathrm{MOH}_{2}^{+} \mathrm{S}^{-}\right)}{\left(\mathrm{MOHS}^{-} \mathrm{C}^{+} \cdot \mathrm{MOH}_{2}^{+} \mathrm{S}^{-}\right)}
\end{aligned}
$$

where

$$
\begin{aligned}
\left(\mathrm{MOH}_{2}^{+} \mathrm{S}^{-}\right)= & \begin{array}{l}
\text { concentration of positively charged sites } \\
\text { complexed with negative surfactant ions }
\end{array} \\
\left(\mathrm{MOHS}^{-} \mathrm{C}^{+\cdot} \cdot \mathrm{MOH}_{2}^{+} \mathrm{S}^{-}\right)= & \begin{array}{l}
\text { concentration of neutral sites complexed with } \\
\text { neutral surfactant-counterion pai. } s
\end{array}
\end{aligned}
$$

The activities of the ions near the surface differ from their activities in the bulk solution by the electrical work required to bring them to the plane where they reside:

$$
\begin{aligned}
& \left(\mathrm{H}_{0}^{+}\right)=\left(\mathrm{H}_{\text {bulk }}^{+}\right) \exp \left(\frac{-\mathrm{e} \Psi_{0}}{\mathrm{kT}}\right) \\
& \left(C_{B}^{+}\right)=\left(C_{\text {eq }}\right) \exp \left(\frac{-\mathrm{e} \psi_{B}}{\mathrm{kT}}\right)
\end{aligned}
$$

In addition to an electrostatic effect, the activity of a surfactant ion near the surface is also influenced by the hydrophobic effect:

$$
\left(S_{B}^{*}\right)=\left(S_{e q}\right) \exp \left(\frac{+\Psi_{B}}{k^{\prime}}\right) \exp \left(\frac{\omega \theta}{k T}\right)
$$

where

$$
\omega \quad=\quad \text { lateral interaction energy }
$$




$$
\begin{aligned}
\theta & =\text { fractional surface coverage } \\
& =\frac{\text { adsorption density } \Gamma_{S} \text { at equilibrium }}{\text { adsorption density } \Gamma_{\text {monolayer }} \text { at monolayer coverage }} \\
\left(\mathrm{MOH}^{*}\right) & =\text { concentration of active neutral sites } \\
& =(\mathrm{MOH})[1-q] \\
& \Gamma_{S}=-\frac{\left(\mathrm{MUH}_{2}^{+} \mathrm{S}^{-}\right)+\left(\mathrm{MOHS}^{-} \mathrm{C}^{+} \cdot \mathrm{MOH}_{2}^{+} \mathrm{S}^{-}\right)}{(\text {surface area per unit volume })}
\end{aligned}
$$

The special nature of the surfact unt, ...amely the hydrophobic effect, is accounted for in this model in several ways. In the lirst reaction, interaction of the hydrocarbons tails with the surface is accounted for through the value of the equilibrium constant $\mathrm{K}_{\mathrm{S}}^{\mathrm{int} *^{*}}$, which is less than equilibrium constants for anions without hydruphobic moiety. The lower value means that surfactant ions are preferentially complexed at positive sites over other anions present in solution. In both reactions, tail-tail interaction is accounted for through the term $\exp (\omega \theta / \mathrm{kT})$, which is a function of surface coverage $\theta$ and laieral interaction energy $\omega$ of the tails. As surface coverage increases, the term increases; and since it multiplies the complex concentration term, the net effect is the enhancement of complexation (or, equivalently, adsorption) with increasing surface coverage. In the second reaction, tail-tail interaction is also accounted for through the dipendence of neutralsite adsorption on positive-site adsorption. As the surface environment becomes more hydrophobic with increasing coverage of positive sites, in-filling by neutral surfactantcounterion pairs is favored.

With the addition of surfactant to the system, the model expands to 17 nonlinear equations with 17 variables. The critical assumption made is that the equilibrium constants determined for the system without surfactant do not change when surfactant is present. The adjustable parameters to be desermined in this case, then, are $\mathrm{K}_{\mathrm{S}}^{\mathrm{int}}, \mathrm{K}_{\mathrm{SC}}^{\mathrm{int}}$, and $\omega$. The criteria used in determining the best values of these parameters are now the experimentally determined values of adsorption density, equilibrium surfactant concentration, surface charge density, and zeta potential wherr available. 


\section{References}

1. Davis, J. A., R. O. James, and J. O. Leckie, L. Colloid Interface Sci., 63, 480 (1978).

2. Davis, J. A., R. O. James, and J. O. Leckie, L. Colloid Ir erface Sai, 67, 90 (1978).

3. James, R. O., and T. W. Healy, L Colloid Interface Sci, 40, 42 (1972).

4. James, R. O., J. A. Davis, and J. O. Leckie, L Colloid. "iterface Sci, 65, 331 (1978).

5. James, R. O., and G. A. Parks, in Surface and Colloid Science. E. Mats -vic, (ed.), Wiley Interscience, New York City (1982) 12, 119.

6. Yates, D. E., S. Levine, and T. W. Healy, L. Chem Soc. Faraday Trans., 70, 1807 (1974). 

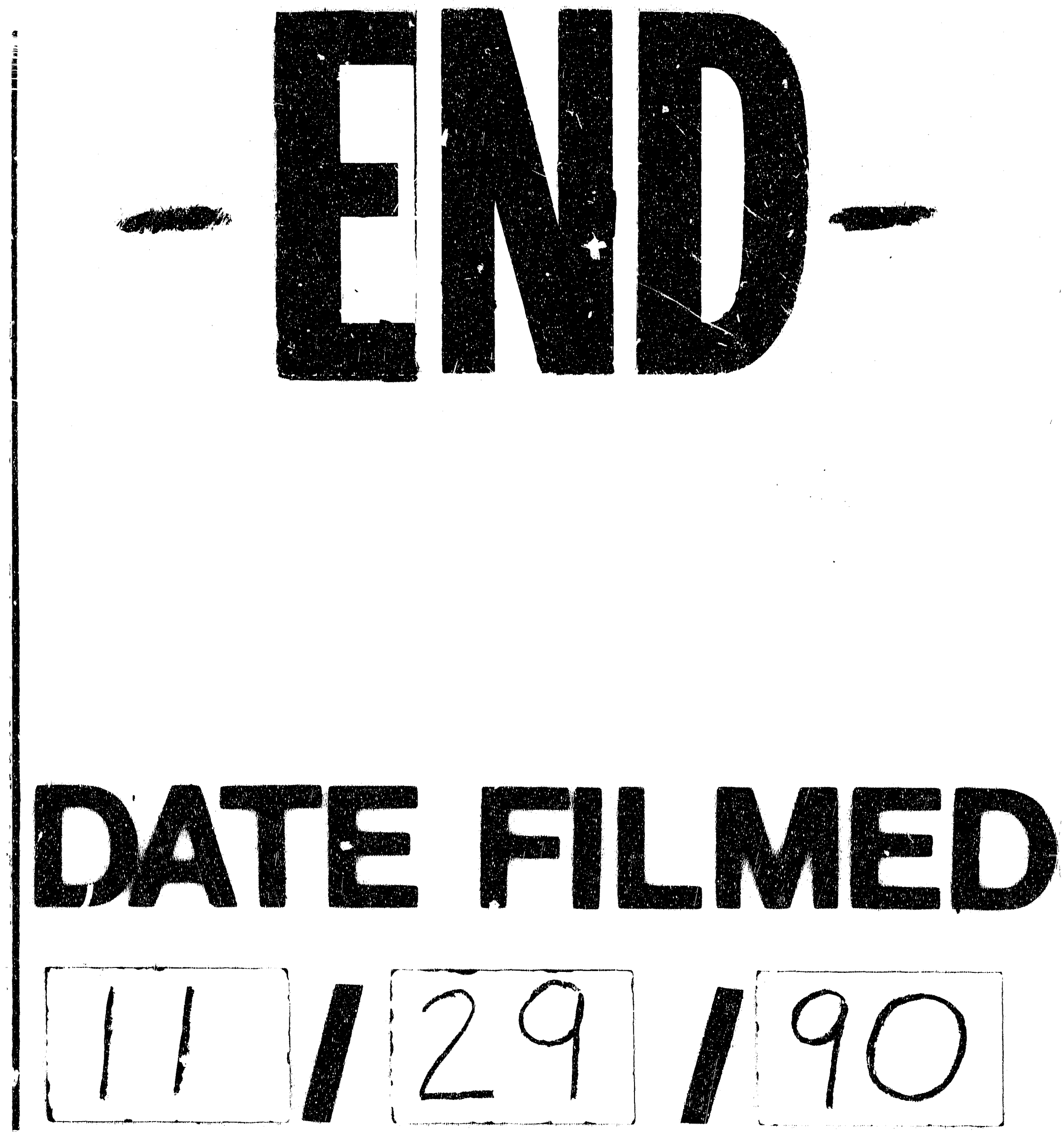


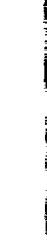

